\title{
Deoxidation of Molybdenum during Vacuum Sintering
}

\begin{abstract}
H.S. HUANG and K.S. HWANG
Molybdenum is usually fabricated through the powder metallurgy (P/M) process, using fine powders with a relatively high oxygen content. Oxygen, however, is one of the main elements causing embrittlement during the deformation processing of molybdenum, such as rolling, extrusion, and forging. Thus, how to deoxidize the compact as completely as possible is critical in the P/M process. This study shows that, as an alternative to hydrogen reduction, molybdenum oxides can be reduced by adding organic lubricants to the compact and by sintering the compact under high vacuum with long sintering times. After 10 hours of sintering at $1750{ }^{\circ} \mathrm{C}$ and a 0.03 torr vacuum, the oxygen content decreased from $0.927 \mathrm{wt}$ pct of the green compact to $0.017 \mathrm{wt}$ pct. The ductility also improved significantly compared to compacts sintered for 5 hours, which contained 0.218 wt pct oxygen. The morphology evolution, weight changes, and the X-ray analysis indicated that the oxide was first present in the form of $\mathrm{MoO}_{3}$. It was then transformed into $\mathrm{MoO}_{2}$ before deoxidation was completed. Two deoxidation mechanisms were identified: evaporation and decomposition of $\mathrm{MoO}_{3}$ and $\mathrm{MoO}_{2}$, with evaporation being dominant in the early-stage sintering and decomposition being dominant in the later stage.
\end{abstract}

\section{INTRODUCTION}

THE high melting point, low thermal-expansion coefficient, and high thermal/electrical conductivity make molybdenum a popular material for power semiconductor components, glass-melting electrodes, and high-temperature structural parts. These molybdenum parts are mostly fabricated through the powder metallurgy $(\mathrm{P} / \mathrm{M})$ process, in which fine molybdenum powders and high sintering temperatures are used in order to obtain high sintered densities. Without adequate care, the deformability and weldability of P/Mprocessed molybdenum are, however, less than desirable. ${ }^{[1,2,3]}$ The main reason is that the oxygen content is usually high in the starting powder, so oxides are easily segregated at the grain boundaries during sintering. This causes intergranular brittle fracturing even at room temperatures. ${ }^{[3,4,5]}$ Previous studies suggested that to endure heavy mechanical deformation, such as extrusion, rolling, and forging, the oxygen content must be lower than $200 \mathrm{ppm}^{[3]}$ and even as low as $50 \mathrm{ppm} .{ }^{[4,6]}$ One way to reduce the oxygen content in the sintered molybdenum is to start with clean powders and to sinter them in hydrogen. The obvious advantage of using hydrogen is its capability to reduce molybdenum oxides. Vacuum sintering is another process frequently used, because it has lower operational cost and the deoxidation can take place under a high degree of vacuum. Brewer and Rosenblatt showed that molybdenum and tungsten oxides both have relatively high evaporation rates compared to most other metals. ${ }^{[7]}$ When high vacuum and high temperatures are employed, these metals can be deoxidized through evaporation of their volatile oxides. ${ }^{[8]}$ In addition, the thermodynamics also suggests that molybdenum oxides can be decomposed when the oxygen partial pressure is low enough or when reducing agents, such as carbon, are present.

Although the deleterious effect of oxygen on the ductility

H.S. HUANG, Graduate Student, and K.S. HWANG, Professor, are with the Department of Materials Science and Engineering, National Taiwan University, Taipei 106, Taiwan, Republic of China. Contact e-mail: kshwang@ccms.ntu.edu.tw

Manuscript submitted June 4, 2001. of molybdenum has been known for some time, little information is available on how and to what extent the sintering parameters will influence the oxygen content. The detailed mechanism of deoxidation of molybdenum compacts under vacuum is also unclear. The first objective of this study was, thus, to investigate the effects of the sintering time, the sintering atmosphere, and the organic lubricant on the mechanical properties of molybdenum compacts. The second objective was to analyze the changes in the content of oxygen, carbon, and nitrogen and the microstructure evolution through different stages of sintering, so that the deoxidation mechanism can be better understood.

\section{EXPERIMENTAL PROCEDURE}

Fine molybdenum powder, with an average particle size of $2.5 \mu \mathrm{m}$, was selected for this study. The characteristics and the morphology of the powder are given in Table I and Figure 1, respectively. Due to the large surface area of the powder, the oxygen content is quite high, at a level of 0.927 wt pct. The oxygen was present in the form of $\mathrm{MoO}_{3}$, as was identified by X-ray photoelectron spectroscopy (MT500, VG MICROTECH Co., East Grinstad, United Kingdom) and as shown in Figure 2. Based on the oxygen content of $0.927 \mathrm{wt}$ pct and its solubility of less than $0.001 \mathrm{wt}$ pct in molybdenum, ${ }^{[9,10]}$ there was as much as $2.7 \mathrm{wt}$ pct $\mathrm{MoO}_{3}$ on the powder surfaces.

The molybdenum powder was compacted into 65-pctdense rectangular bars, $40 \times 15 \times 4.3 \mathrm{~mm}$, at a pressure of $450 \mathrm{MPa}$. The first group of the green compacts was heated at $10{ }^{\circ} \mathrm{C} / \mathrm{min}$ to $1750{ }^{\circ} \mathrm{C}$ and then held isothermally for $5,10,20,40$, and 100 hours under a vacuum of $4 \mathrm{~Pa}$ (0.03 torr). The second group was heated to $1000{ }^{\circ} \mathrm{C}$ and held for 30 minutes in hydrogen to reduce the surface oxides. They were subsequently sintered at $1750{ }^{\circ} \mathrm{C}$ for 5 hours under vacuum. The powder in the third group contained 0.5 wt pct ethylene bis-stearamide (EBS), which is an organic lubricant commonly used in pressing metal powders. This lubricant was added in an attempt to remove oxygen with the carbon. The compacts in this third group were sintered under the same condition as the first group. 
Table I. Characteristics of the Molybdenum Powder Used in This Study

\begin{tabular}{ll}
\hline Molybdenum Powder & Characteristics \\
\hline Grade & OMP901 \\
Supplier & CSM Industries \\
Particle size & \\
$D_{10}$ & $1.0 \mu \mathrm{m}$ \\
$D_{50}$ & $2.5 \mu \mathrm{m}$ \\
$D_{90}$ & $5.8 \mu \mathrm{m}$ \\
BET surface area & $0.85 \mathrm{~m}^{2} / \mathrm{g}$ \\
Shape & irregular \\
Density (pycnometer) & $10.18 \mathrm{~g} / \mathrm{cm}^{3}$ \\
Chemistry & \\
C, pct & 0.0019 \\
S, pct & 0.0013 \\
O, pct & 0.9270 \\
N, pct & 0.0088 \\
\hline
\end{tabular}

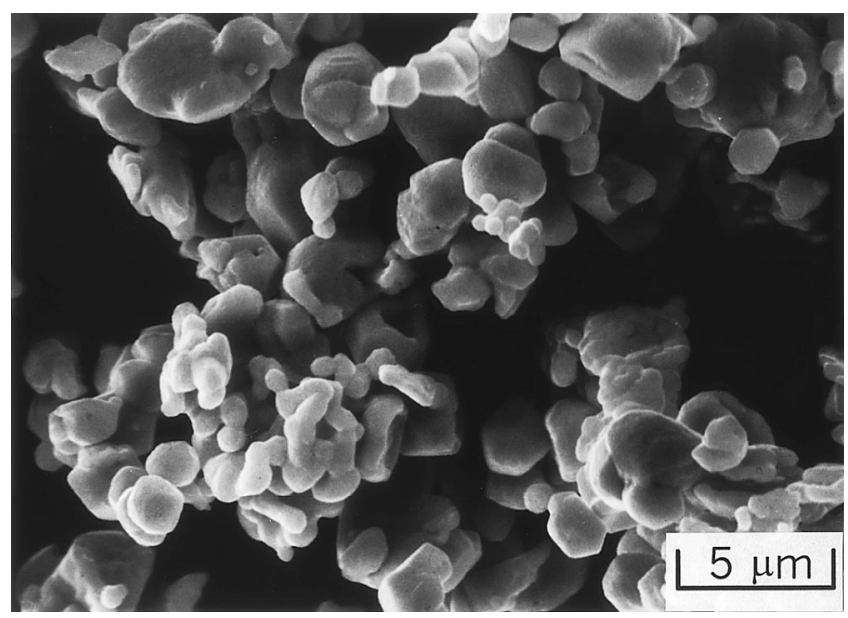

Fig. 1-The morphology of the molybdenum powder used in this study.

To measure the $\mathrm{C}, \mathrm{N}$, and $\mathrm{O}$ content in powders, green compacts, and sintered specimens, a LECO* CS-244 carbon

*LECO is a trademark of the LECO Corporation, St. Joseph, MI.

analyzer and a TC-136 oxygen/nitrogen analyzer (LECO Corporation, St. Joseph, MI) were employed. The energydispersive X-ray spectrometer (EDS) (PV9900, EDAX Inc., Mahwah, NJ) and X-ray diffractometer (PW1830, PHILIPS*

*PHILIPS is a trademark of Philips Electronic Instruments Corp., Mahwah, NJ.

Co., Eindhoven, Holland) were also employed to determine if oxides were present after sintering. To examine the fracture surface and the detailed microstructure of the specimens, a field-emission scanning electron microscope was used (LEO-1530, LEO Electron Microscopy Ltd, Cambridge, United Kingdom).

The density of compacts was measured by the Archimedes' method. To examine the fracture surface and the ductility, specimens were ruptured by the four-point bend test at a crosshead speed of $2.5 \mathrm{~mm} / \mathrm{min}$. The grain size was measured by the line-intercept technique from metallographs taken by the scanning electron microscopes. The reported

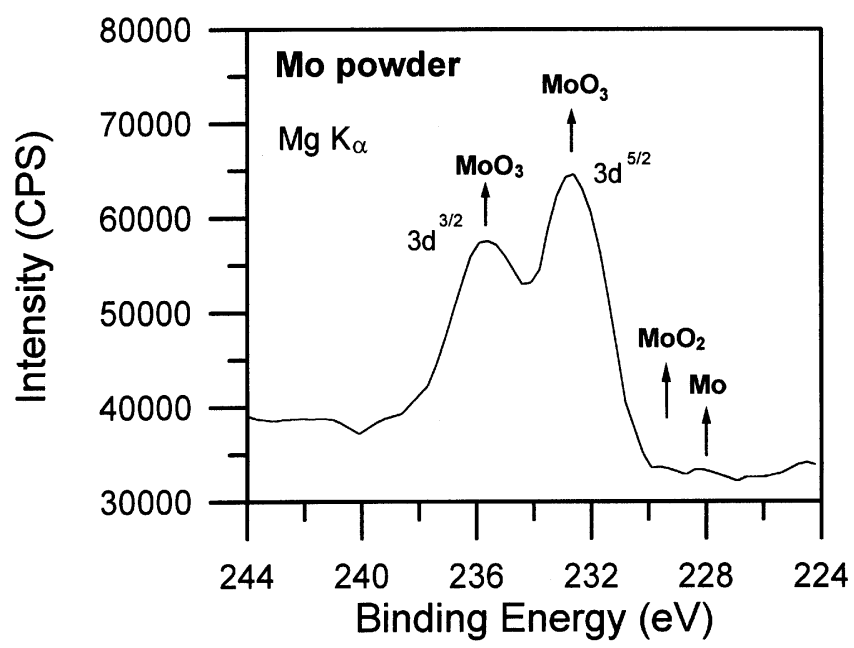

Fig. 2-The XPS spectrum of the as-received molybdenum powder, showing that $\mathrm{MoO}_{3}$ is present on powder surfaces.

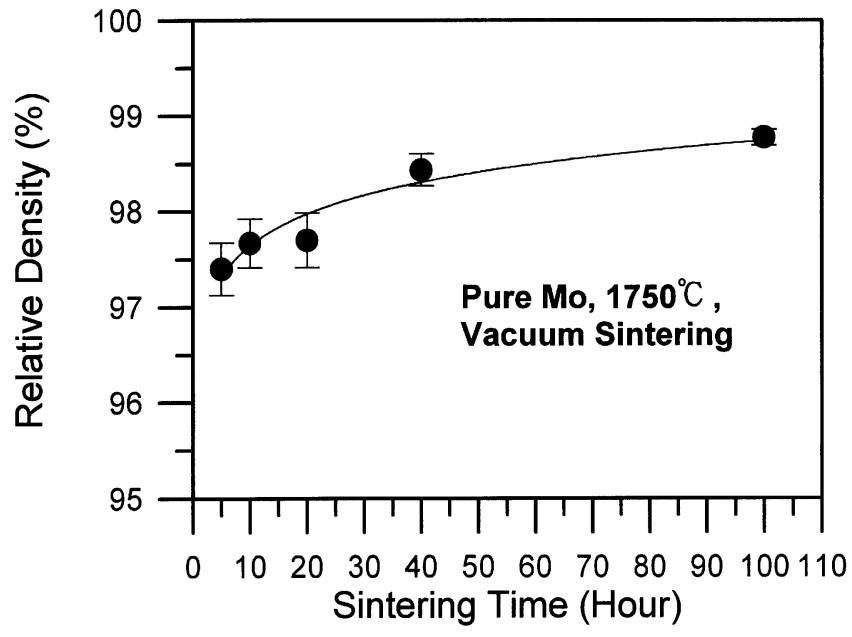

Fig. 3-The effect of sintering time on the density of sintered molybdenum compacts.

density, grain size, and hardness data are an average of at least five measurements.

\section{RESULTS}

\section{A. Direct Vacuum Sintering}

Figure 3 shows that, after 5 hours of sintering, the density attained a $97.4 \mathrm{pct}$ theoretical density. As the sintering time further increased, the sintered density increased only slightly. After 100 hours of sintering, the density reached 98.8 pct. The microstructure that was taken from the center section of the specimen sintered for 5 hours indicated that there were second phases. They were mostly located at the triple points and at the grain boundaries, as shown in Figure 4(a). The EDS spectrum indicated that these second phases contained large amounts of oxygen. The X-ray diffraction pattern, as shown in Figure 5, confirmed that they were $\mathrm{MoO}_{2}$. The amount of the oxide, estimated from Figure 4(a) by the quantitative metallography method, is 5.5 pct. It should be noted, however, that the oxide content decreases toward the outer section of the specimen. When the sintering time 


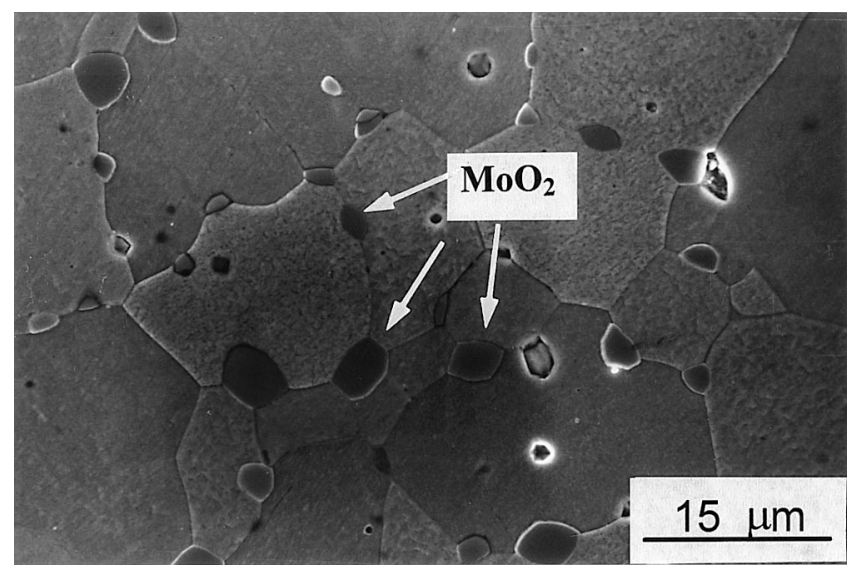

(a)

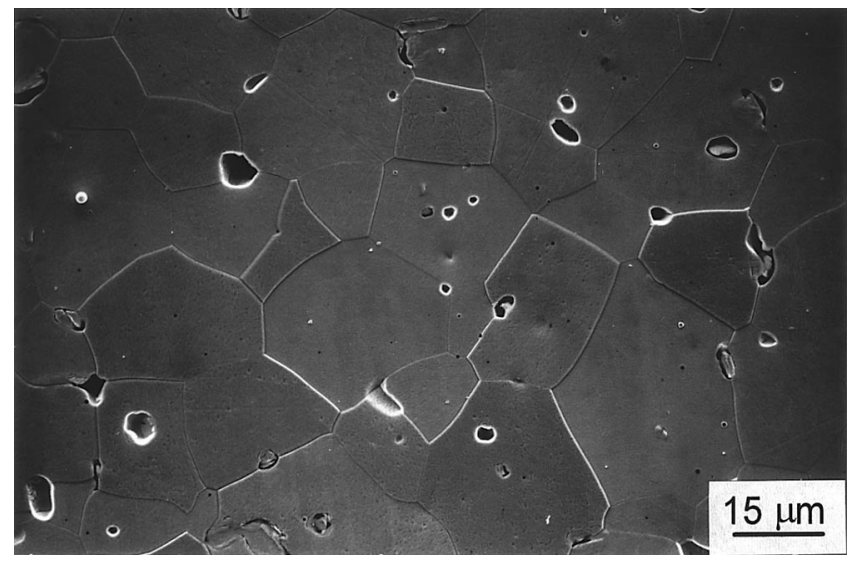

(b)

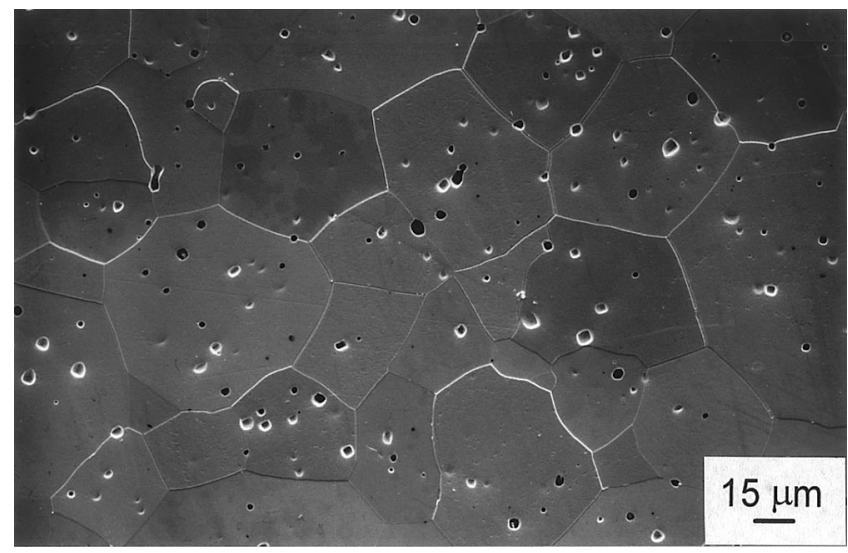

(c)

Fig. 4-The SEM micrograph taken from the center section of the specimen sintered for $(a) 5 \mathrm{~h},(b) 10 \mathrm{~h}$, and (c) $100 \mathrm{~h}$.

increased to 10 and 100 hours, no oxide was found, even at the center section, as shown in Figures 4(b) and (c). Since there were no more second phases to pin the grain-boundary movement, the grain size increased rapidly from $17.5 \mu \mathrm{m}$ in the compacts sintered for 5 hours to $57.1 \mu \mathrm{m}$, as shown in Figure 6. The grain growth rate then slowed significantly and reached 66, 69, and $72 \mu \mathrm{m}$ after 20, 40, and 100 hours of sintering, respectively.

Figure 7 shows that the hardness reached HRB 84 after 5 hours of sintering. It then decreased slightly as the sintering

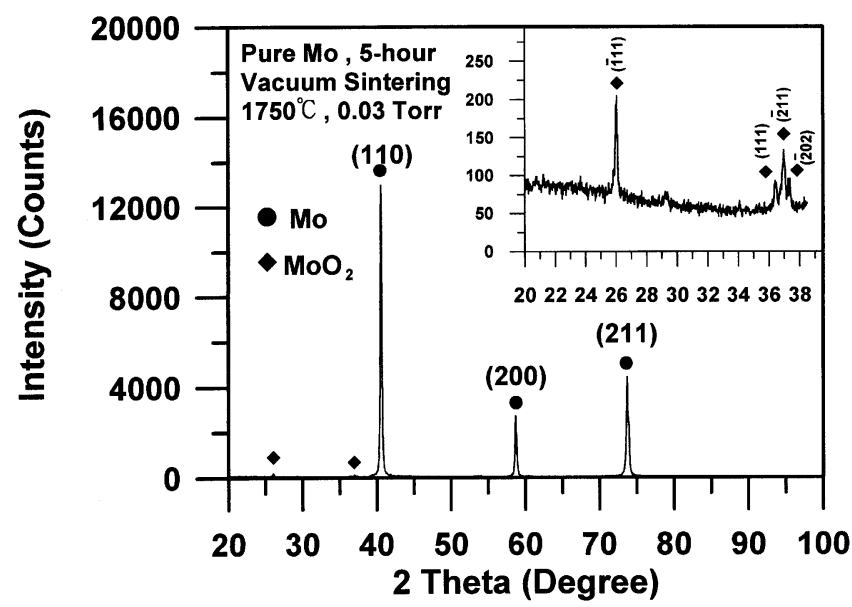

Fig. 5-The X-ray diffraction pattern of the specimen vacuum sintered for $5 \mathrm{~h}$, showing the presence of $\mathrm{MoO}_{2}$ phase.

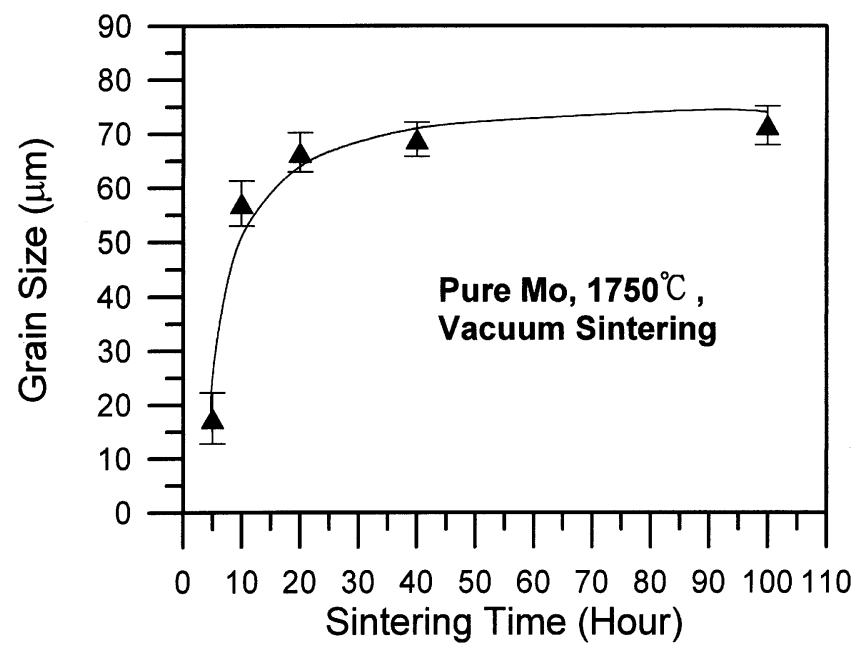

Fig. 6-The grain size increased significantly after being sintered for 10 $\mathrm{h}$. The grain growth rate then slowed with longer sintering times.

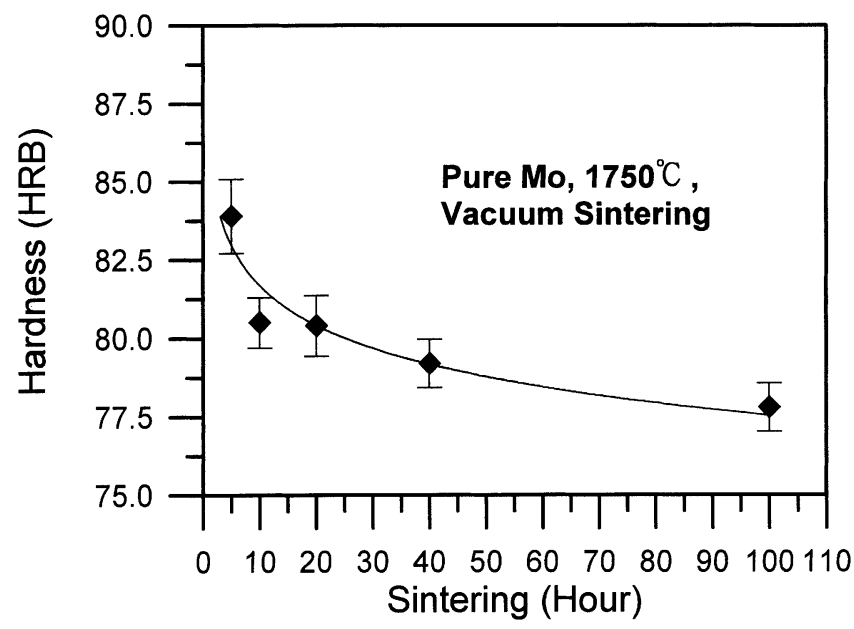

Fig. 7-The hardness decreased slightly as the sintering time increased due to the grain growth effect.

time increased, despite a small increase in density. This suggests that the decrease in hardness was mainly attributed to the increase in the grain size. 


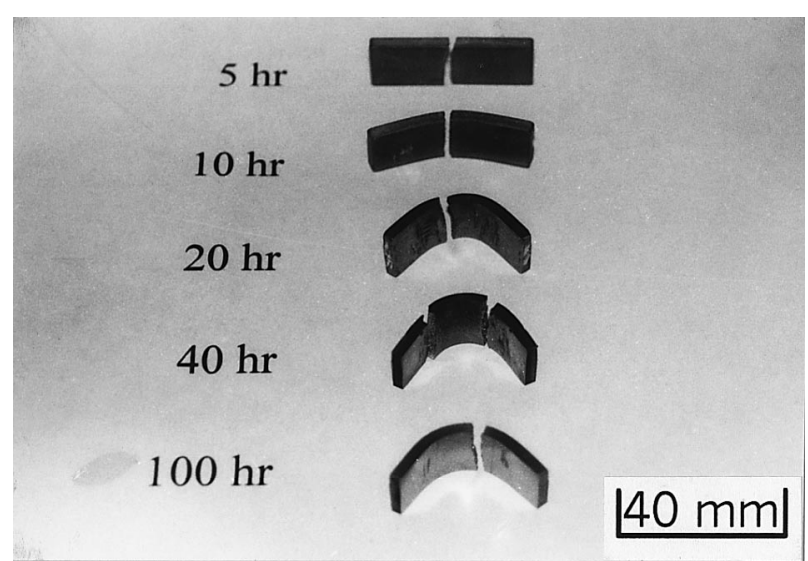

Fig. 8-The four-point bend tests showing that the fracture mode changed from the brittle type to the ductile type after compacts were sintered for $10 \mathrm{~h}$ and longer.

Figure 8 shows the results of the four-point bend test. The specimen sintered for 5 hours fractured in a brittle mode. All fracture surfaces were of the intergranular type, and oxide particles were found at the grain surfaces, as exhibited in Figure 9(a). It is believed that these oxide particles located at the triple points and at the grain boundaries are the main culprits in initiating the voids that propagate and cause fractures. In contrast, after 10 and 100 hours of sintering, specimens showed plastic deformation prior to fracture (Figure 8). Figures 9(b) and (c) reveal that the oxides that were present after 5 hours of sintering disappeared. The fracture surfaces were mixed, with intergranular and transgranular types. These microstructures suggest that the improvement in ductility is very likely related to the elimination of the oxide particles located at the grain boundaries and at the triple points.

Since the mechanical properties of molybdenum are strongly affected by the amount of $\mathrm{C}, \mathrm{N}$, and $\mathrm{O}$, their contents were monitored closely, as shown in Figure 10 for carbon and nitrogen and in Figure 11 for oxygen. The carbon content was independent of the sintering time and was about 20 ppm. In contrast, the nitrogen decreased significantly from $88 \mathrm{ppm}$ in the as-received powder to less than $10 \mathrm{ppm}$ after 10 hours of sintering. This can very likely be attributed to the desorption of nitrogen from the surface. ${ }^{[11]}$ The oxygen content also drastically decreased from 9270 to $2180 \mathrm{ppm}$ when the green compact was sintered for 5 hours. It further decreased to $168 \mathrm{ppm}$ after 10 hours of sintering and to 94 ppm after 20 hours of sintering.

To illustrate the oxygen distribution in the compact sintered for 5 hours, the top and bottom $1 \mathrm{~mm}$ sections of the 4-mm-thick specimen were machined off, and their oxygen contents were measured and compared to that of the center section. The core section showed $1022 \mathrm{ppm}$ more oxygen than the outer sections. This suggests that the deoxidation process started from the outside and progressed toward the inside as sintering proceeded.

\section{B. Evolution of Molybdenum Oxides and Microstructures}

To understand how $\mathrm{MoO}_{3}$ in the as-received Mo powder evolves during sintering, pure $\mathrm{MoO}_{3}$ compacts with 50 pct density were heated under vacuum to $700{ }^{\circ} \mathrm{C}, 900{ }^{\circ} \mathrm{C}$, and

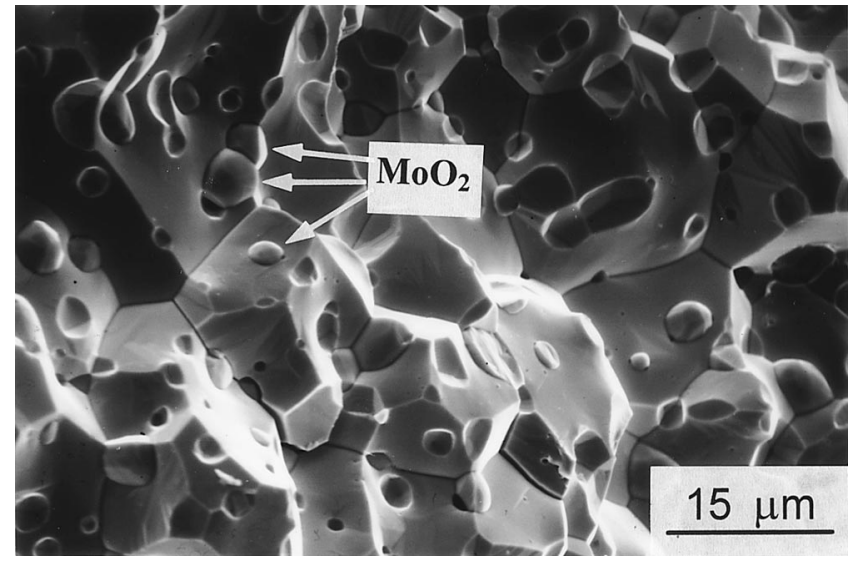

(a)

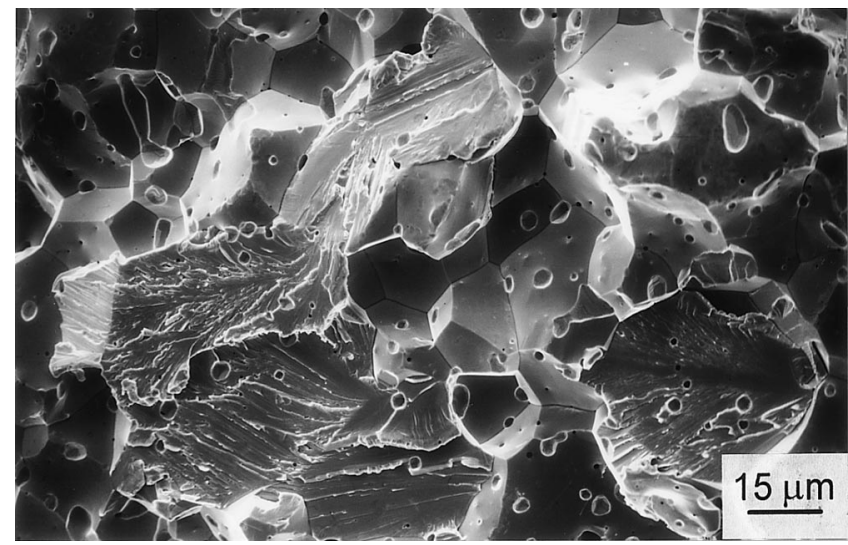

(b)

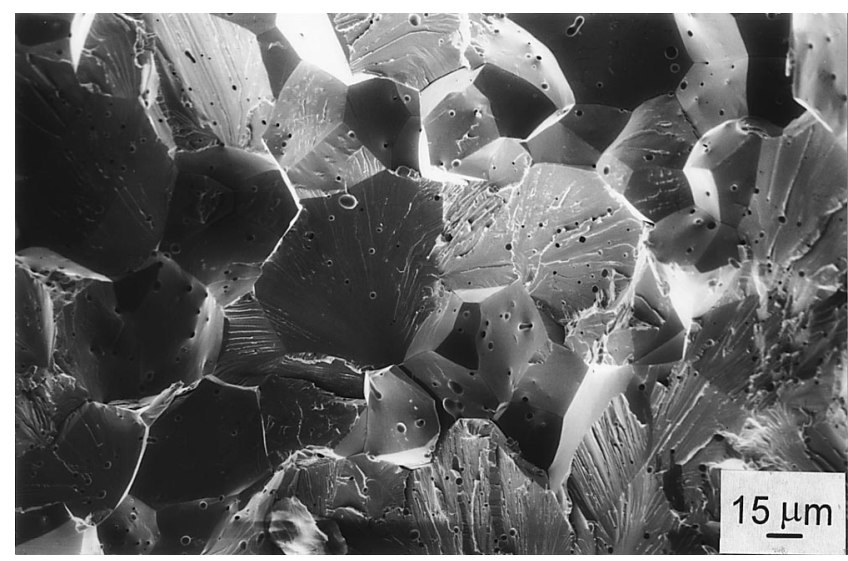

(c)

Fig. 9-The fracture surfaces of specimens after (a) $5 \mathrm{~h},(b) 10 \mathrm{~h}$, and (c) $100 \mathrm{~h}$ of sintering.

$1300{ }^{\circ} \mathrm{C}$, respectively. The compact that was heated to 700 ${ }^{\circ} \mathrm{C}$ lost 29 wt pct. The other two compacts disappeared after being cooled to room temperature. This suggests that $\mathrm{MoO}_{3}$ has a high vapor pressure and can evaporate easily under vacuum, particularly after it melts and becomes liquid at $800{ }^{\circ} \mathrm{C}$. However, in the case of dense compacts, the $\mathrm{MoO}_{3}$ in the center section may not be able to evaporate and subsequently escape to the surface, due to the long distance and the high local gas pressure in the pore channels.

To confirm that, two special molybdenum compacts were made with a 50-pct dense $\mathrm{MoO}_{3}$ preform located in the 


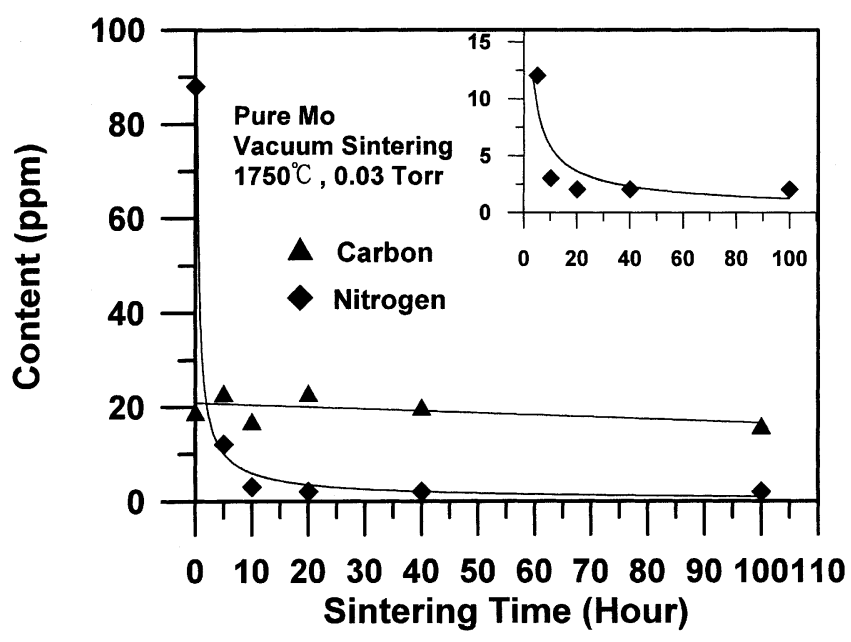

Fig. 10-The changes in carbon and nitrogen content in specimens sintered at $1750{ }^{\circ} \mathrm{C}$ from 5 to $100 \mathrm{~h}$.

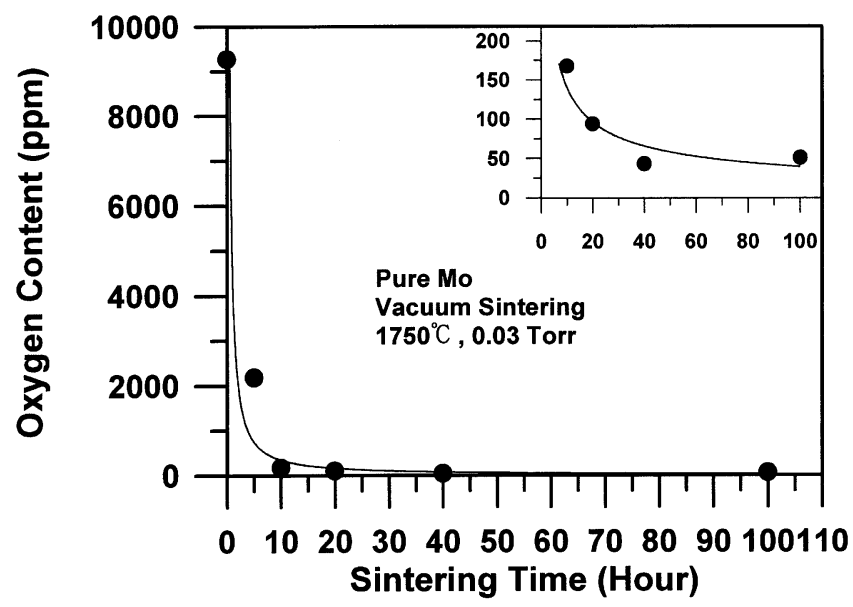

Fig. $11-$ The changes in oxygen content in specimens sintered at $1750{ }^{\circ} \mathrm{C}$ from 5 to $100 \mathrm{~h}$.

center. The specimens were compacted at $450 \mathrm{MPa}$, with the density of the molybdenum in the outer section being about 65 pct dense. They were then heated, respectively, to $700{ }^{\circ} \mathrm{C}$ and $900{ }^{\circ} \mathrm{C}$; one temperature setting is below, and the other one is above, the melting point of the $\mathrm{MoO}_{3}$, which is $800{ }^{\circ} \mathrm{C}$.

After being heated to $700{ }^{\circ} \mathrm{C}$, the center $\mathrm{MoO}_{3}$ remained in place, but a thin layer of brown $\mathrm{MoO}_{2}$ was observed at the $\mathrm{MoO}_{3} / \mathrm{Mo}$ interface due to the reaction between $\mathrm{Mo}$ and $\mathrm{MoO}_{3}$. A sketch is shown in Figure 12(a). When the compact was heated to $900{ }^{\circ} \mathrm{C}$, the $\mathrm{MoO}_{3}$ core disappeared, leaving an empty cavity. However, the brown $\mathrm{MoO}_{2}$ layer formed around the cavity and was much thicker than that in the compact heated to $700{ }^{\circ} \mathrm{C}$, as illustrated in Figure 12(b). This suggests that when the $\mathrm{MoO}_{3}$ melted at $800{ }^{\circ} \mathrm{C}$, the liquid infiltrated into the surrounding powder and reacted with the molybdenum, forming $\mathrm{MoO}_{2}$.

To determine if similar behavior will occur in a molybdenum compact, the regular $40 \times 15 \times 4.3 \mathrm{~mm}$ compacts were heated under vacuum to $700{ }^{\circ} \mathrm{C}, 900{ }^{\circ} \mathrm{C}$, and $1300{ }^{\circ} \mathrm{C}$, respectively. The sintered bars were fractured using a fourpoint bend tester. One side of the broken specimens was used for the examination of the fracture surface, while the

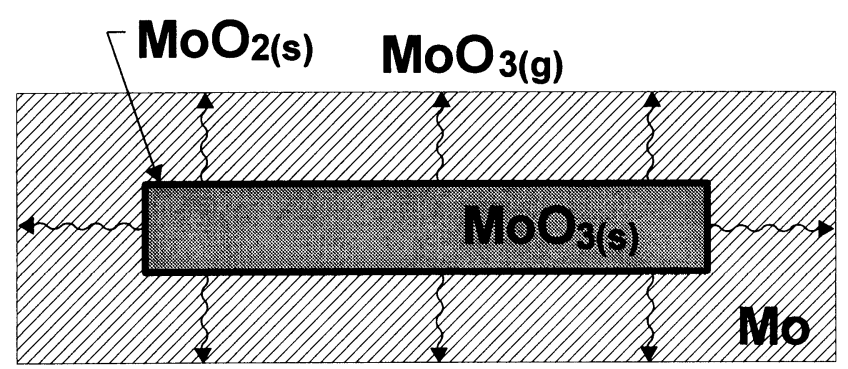

(a)

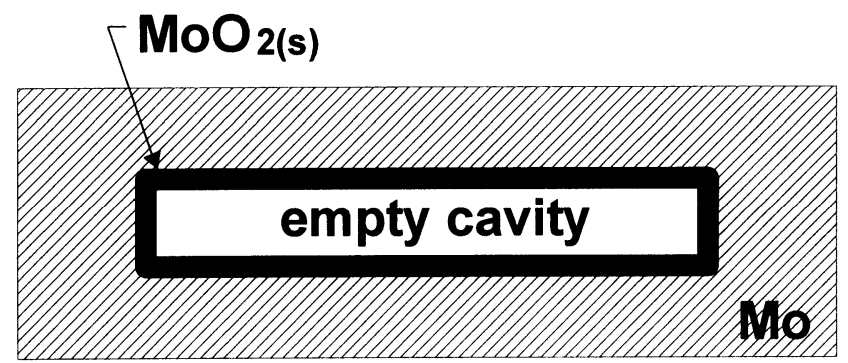

(b)

Fig. 12-(a) The $\mathrm{MoO}_{3}$ core in the molybdenum compact remained and formed a thin layer of $\mathrm{MoO}_{2}$ after being heated to $700{ }^{\circ} \mathrm{C}$. (b) The $\mathrm{MoO}_{3}$ core disappeared and formed a thick layer of $\mathrm{MoO}_{2}$ after being heated to $900{ }^{\circ} \mathrm{C}$.

other side was cut into two halves so that the cross section could be examined for its X-ray diffraction pattern. Figure 13 indicates that very small amounts of $\mathrm{MoO}_{2}$ were present in the specimens heated to those three temperature settings. No $\mathrm{MoO}_{3}$ was detected. The fracture surface shown in Figure 14(a) illustrates that the Mo powder surface was covered with a thin layer of submicron particles. As the temperature increased to $900{ }^{\circ} \mathrm{C}$, these fine particles coarsened and the thin layer was broken in some areas, as illustrated in Figure 14(b). As the temperature further increased to $1300{ }^{\circ} \mathrm{C}$, the oxide particles became discrete and were dispersed on the Mo powder surfaces, as shown in Figure 14(c). These results suggest that all of the $\mathrm{MoO}_{3}$ on the surface of the as-received molybdenum powders had already reacted with Mo and formed submicron $\mathrm{MoO}_{2}$ particles below the melting point of $\mathrm{MoO}_{3}$, at $800{ }^{\circ} \mathrm{C}$. They then coarsened as the temperature increased.

To understand how the deoxidation of the $\mathrm{MoO}_{2}$ proceeds, a pure dark-brown $\mathrm{MoO}_{2}$ compact with 50 pct green density was heated at $10{ }^{\circ} \mathrm{C} / \mathrm{min}$ to $1300{ }^{\circ} \mathrm{C}$ and then cooled to room temperature. The weight loss of the compact was insignificant, as a result of the lower vapor pressure compared to that of $\mathrm{MoO}_{3}$. When the $\mathrm{MoO}_{2}$ compact was further heated to $1750{ }^{\circ} \mathrm{C}$ and then held for 5 hours under vacuum, the compact lost $68 \mathrm{wt}$ pct, more than the oxygen content in $\mathrm{MoO}_{2}$, at $25 \mathrm{wt}$ pct. The remaining compact was gray in color, and the X-ray diffraction pattern confirmed that it was pure molybdenum. The calculation from the weight change indicates that 58 wt pct of the $\mathrm{MoO}_{2}$ evaporated, while the remaining $42 \mathrm{wt}$ pct $\mathrm{MoO}_{2}$ decomposed and became pure molybdenum.

\section{Vacuum Sintering with Pretreatment}

To help remove molybdenum oxides prior to the final sintering, two pretreatment experiments were carried out. 


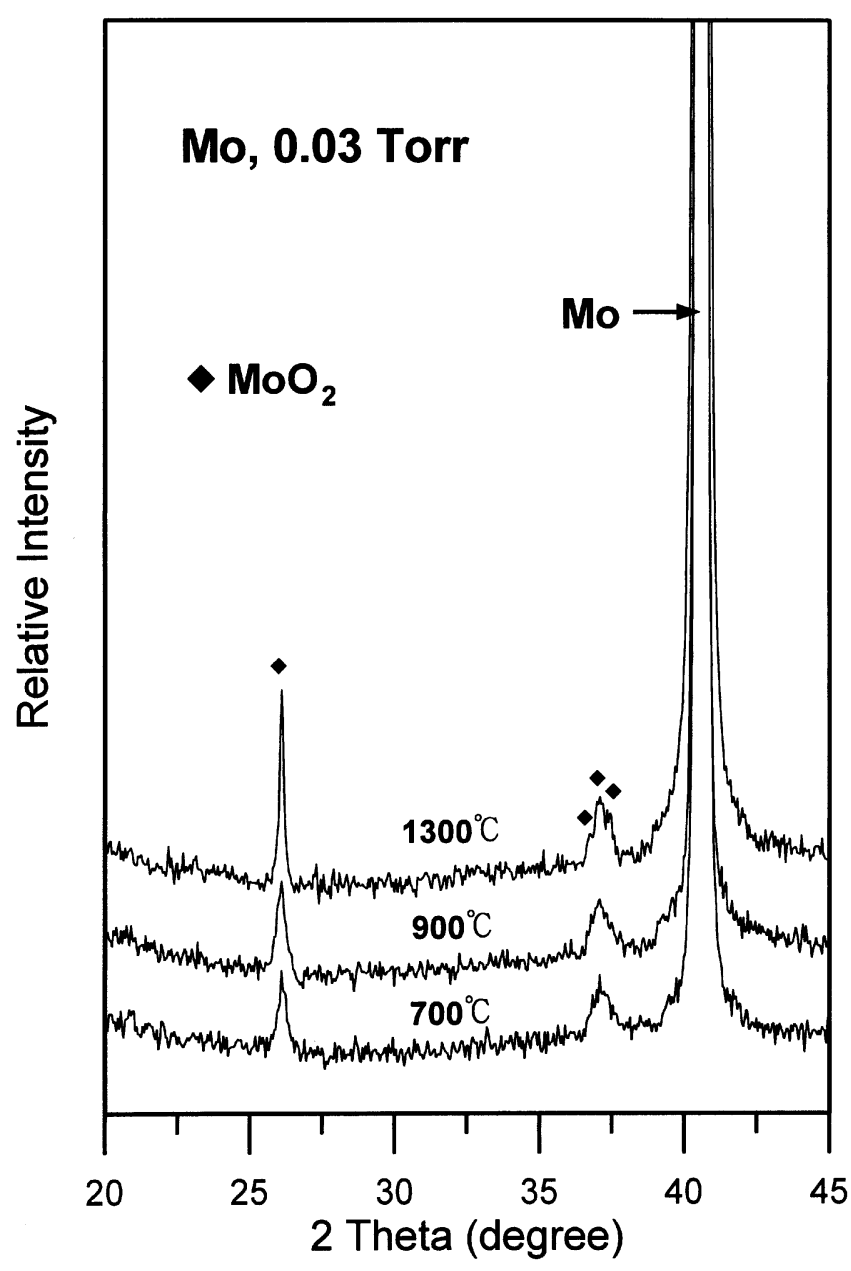

Fig. 13-The X-ray diffraction pattern of the cross section of compacts that were heated to $700{ }^{\circ} \mathrm{C}, 900{ }^{\circ} \mathrm{C}$, and $1300{ }^{\circ} \mathrm{C}$, respectively, shows the presence of $\mathrm{MoO}_{2}$

The first one was to presinter the compacts at $1000{ }^{\circ} \mathrm{C}$ for 30 minutes under hydrogen. The second one was to add 0.5 wt pct organic lubricant (EBS), with the intent of reducing oxides with the carbon in the lubricant. After presintering in hydrogen, the oxygen content decreased significantly from 9270 to $632 \mathrm{ppm}$. After the subsequent 5 hours of vacuum sintering at $1750{ }^{\circ} \mathrm{C}$, the oxygen content further decreased to $147 \mathrm{ppm}$, as shown in Table II. In contrast, the specimen that was not pretreated still contained $2180 \mathrm{ppm}$ oxygen. In the second group, the specimens that contained lubricant showed decreases in their oxygen content to $126 \mathrm{ppm}$. These two experiments indicated that both hydrogen and the organic lubricant could reduce effectively the molybdenum oxides in the compacts.

Table II also shows that the difference in the density and the nitrogen content among these three groups was insignificant. However, the grain size almost doubled with these two pretreatments. This occurred because there was no $\mathrm{MoO}_{2}$ in the matrix, as there was in the direct-sintered compact, to impede the grain-boundary movement as grain growth occurred.

The carbon content in the compact containing organic lubricant was also higher than in the other groups, at 117 ppm. Although carbon has been shown to be less sensitive

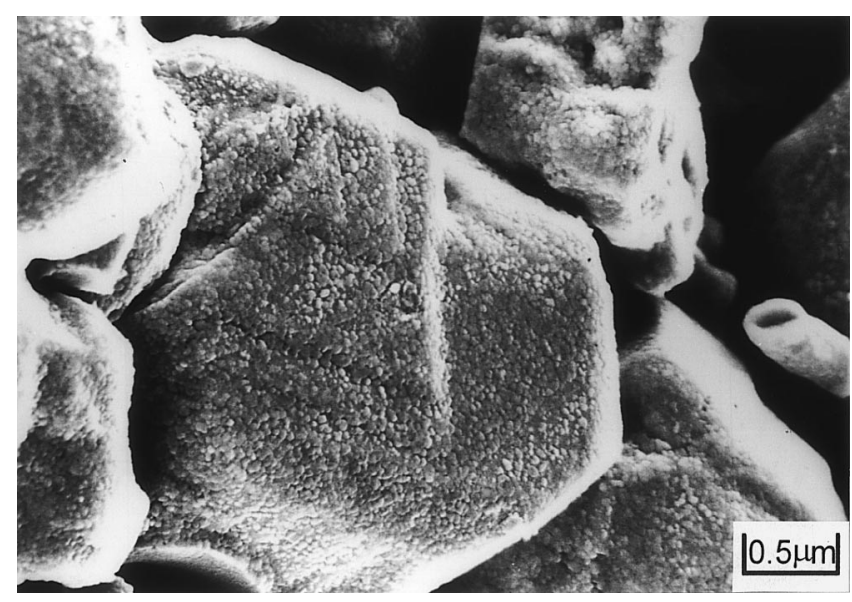

(a)

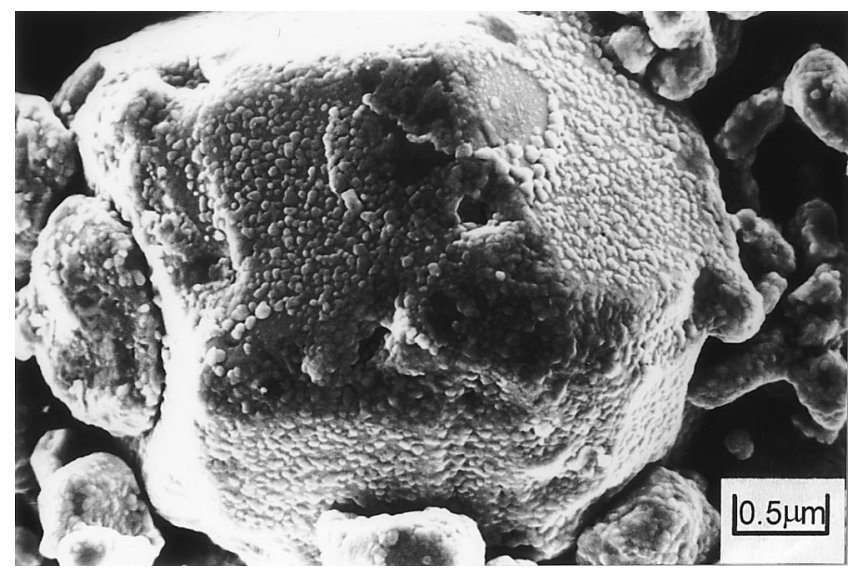

(b)

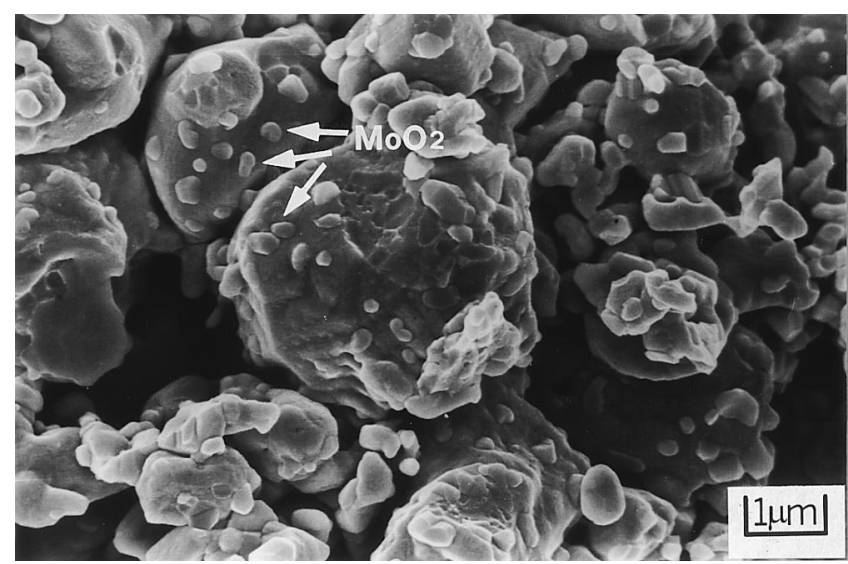

(c)

Fig. 14-The fracture surface of molybdenum compacts that were heated to $(a) 700^{\circ} \mathrm{C},(b) 900^{\circ} \mathrm{C}$, and $(c) 1300{ }^{\circ} \mathrm{C}$, respectively, shows that submicron $\mathrm{MoO}_{2}$ particles (indicated by arrows) coarsened as the temperature increased.

to embrittlement ${ }^{[4]}$ or even strengthens the grain-boundary cohesion, ${ }^{[2,12]}$ the improvement in ductility of this group was not attributed to the increase in carbon. This is because the hydrogen-pretreated group, which had a low carbon content, also fractured in a ductile mode. Thus, the results in Table II strongly suggest that the improvement in ductility of the 
Table II. The Comparison of Sintered Properties for Compacts without Pretreatment, with Presintering at $1000{ }^{\circ} \mathrm{C}$ under Hydrogen, and with 0.5 wt pet EBS Additions

\begin{tabular}{|c|c|c|c|}
\hline & $\begin{array}{c}\text { Directly Sintered } \\
\text { at } 1750{ }^{\circ} \mathrm{C}, 5 \mathrm{~h}\end{array}$ & $\begin{array}{l}\text { With } 30 \mathrm{Min} \mathrm{H}_{2} \\
\text { Reduction at } 1000{ }^{\circ} \mathrm{C}\end{array}$ & $\begin{array}{c}\text { With } 0.5 \mathrm{Wt} \text { Pct } \\
\text { EBS Addition }\end{array}$ \\
\hline Relative density & $97.4 \mathrm{pct}$ & $97.8 \mathrm{pct}$ & $97.1 \mathrm{pct}$ \\
\hline Hardness & HRB 83.9 & HRB 83.3 & HRB 83.5 \\
\hline Grain size & $17.5 \mu \mathrm{m}$ & $33.6 \mu \mathrm{m}$ & $31.1 \mu \mathrm{m}$ \\
\hline Bending test & brittle (342 MPa) & ductile & ductile \\
\hline $\mathrm{C}$ content & $23 \mathrm{ppm}$ & $20 \mathrm{ppm}$ & 117 ppm \\
\hline $\mathrm{N}$ content & $12 \mathrm{ppm}$ & $3 \mathrm{ppm}$ & $4 \mathrm{ppm}$ \\
\hline $\mathrm{O}$ content & $2180 \mathrm{ppm}$ & $147 \mathrm{ppm}$ & $126 \mathrm{ppm}$ \\
\hline
\end{tabular}

compacts with the two pretreatments was mainly a result of the decrease in the oxygen content.

\section{DISCUSSION}

The previous results show that as the sintering time increases, the hardness of molybdenum compacts decreases, despite the slight increase in sintered density. This decrease in hardness is caused by the increase in the grain size, as the Hall-Petch equation predicts. The results also show that the ductility improves with the grain size, which contradicts expectations. Since the change in density is insignificant, this improvement in ductility must be caused by other factors, such as the reductions in the impurity content or second phases at grain boundaries. It is known that the solubility of oxygen in molybdenum is quite low, less than $10 \mathrm{ppm}$ at $25{ }^{\circ} \mathrm{C} .{ }^{[9,10]}$ Thus, oxygen can easily segregate at the grain boundaries, more likely in the oxide form, and make molybdenum brittle at room temperature. ${ }^{[3,4,5]}$ Table II and Figures 8 and 9 confirm that when there was a high oxygen content, the specimens showed intergranular brittle fractures. The amount of oxygen, however, can be reduced by sintering under hydrogen or by adding organic lubricants in the compacts. Moreover, it can also be reduced by sintering under vacuum, as long as the sintering time is long enough, as shown in Figure 11.

Several possible deoxidation reactions that could occur during vacuum sintering are:

$$
\begin{gathered}
\mathrm{MoO}_{3(\mathrm{~s})} \rightarrow \mathrm{MoO}_{3(\mathrm{~g})} \\
\mathrm{Mo}+\mathrm{MoO}_{3(\mathrm{~s}, \mathrm{~g}, \mathrm{l})} \rightarrow 2 \mathrm{MoO}_{2(\mathrm{~s})} \\
\mathrm{MoO}_{2(\mathrm{~s})} \rightarrow \mathrm{MoO}_{2(\mathrm{~g})} \\
\mathrm{MoO}_{2(\mathrm{~s})} \rightarrow \mathrm{Mo}_{(\mathrm{s})}+\mathrm{O}_{2(\mathrm{~g})}
\end{gathered}
$$

Ono and Moriyama ${ }^{[8]}$ indicated that molybdenum oxides have high vapor pressures, $71 \mathrm{~Pa}$ for $\mathrm{MoO}_{3}$ and $8.3 \mathrm{~Pa}$ for $\mathrm{MoO}_{2}$ at $1727{ }^{\circ} \mathrm{C}$. Since these vapor pressures are higher than the $4 \mathrm{~Pa}$ vacuum employed in this study, it is very likely that some deoxidation could be accomplished by the evaporation of the molybdenum oxides. This was in conformity with the experiment in which pure $\mathrm{MoO}_{3}$ disappeared after being heated to $1300{ }^{\circ} \mathrm{C}$, as described in the previous section. However, in 65-pct-dense molybdenum compacts sintered for 5 hours at $1750{ }^{\circ} \mathrm{C}, 2180 \mathrm{ppm}$ oxygen remained in the compact, as shown in Table II. This oxygen was present in the form of $\mathrm{MoO}_{2}$, particularly in the core section, as shown in Figure 4(a). This suggests that most of the $\mathrm{MoO}_{3}$ originally on the powder surface evaporated and escaped to the ambient environment, while the remaining $\mathrm{MoO}_{3}$ was trapped. This could be because the compact did not have enough porosity for vapor transport, and the local vapor pressure in the pore channels was too high to prevent further evaporation of the $\mathrm{MoO}_{3}$. The remaining $\mathrm{MoO}_{3}$ then reacted with molybdenum, forming $\mathrm{MoO}_{2}$. Such a reaction was also confirmed by heating the molybdenum compact that contained a $\mathrm{MoO}_{3}$ core, as illustrated in Figure 12.

As the sintering temperature further increases, two main mechanisms could proceed, causing the deoxidation of $\mathrm{MoO}_{2}$. The first one is by evaporation (Eq. [3]) and the second one is by decomposition (Eq. [4]). However, similar to the experiment with $\mathrm{MoO}_{3}$, the $\mathrm{MoO}_{2}$ located in the center section, as shown in Figures 4 and 14, cannot evaporate and escape to the ambient environment through the dense compact, due to the lesser degree of vacuum in the pore channels in the core section. Moreover, as sintering enters the final stage, all pores are isolated, which further prohibits the evaporation mechanism from occurring. The more plausible deoxidation mechanism at that stage would then be decomposition of $\mathrm{MoO}_{2}$, with the transport of oxygen out of the compact by diffusion.

The thermodynamic calculation indicates that if the oxygen partial pressure in the furnace is equal to or lower than $7.5 \times 10^{-2} \mathrm{~Pa}$, decomposition of $\mathrm{MoO}_{2}$ occurs. ${ }^{[13]}$ That value is much lower than the level possible with the vacuum pump employed. However, the furnace we used in this study was constructed with graphite heaters and graphite felts for heating elements and heat-insulating materials. Because residual oxygen in the atmosphere has a tendency to react with graphite first, the equilibrium oxygen partial pressure in the atmosphere in the furnace was only $1.32 \times 10^{-10} \mathrm{~Pa}$, which is much lower than what is required for the $\mathrm{MoO}_{2}$ to decompose. The deoxidation rate, however, is quite slow, compared to the evaporation mechanism. This is because oxygen atoms released from the decomposition reaction must diffuse through the bulk or the grain boundaries to the surface, which is a slow diffusion-controlled process.

These results suggest that both evaporation and decomposition mechanisms are responsible for the deoxidation of molybdenum. The schematics given in Figure 15 summarize how deoxidation of molybdenum proceeds during vacuum sintering. In the early stage, as the green compact is heated in vacuum, the $\mathrm{MoO}_{3}$ evaporation is the dominant mechanism, and it results in significant oxygen reduction. However, the oxides in the center section of the compact may remain if there is not enough time or the compact is too dense. The residual $\mathrm{MoO}_{3}$ will react with molybdenum and 


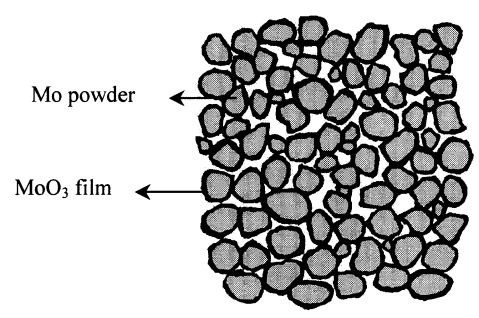

(a)

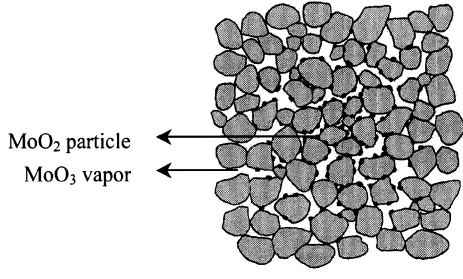

(b)

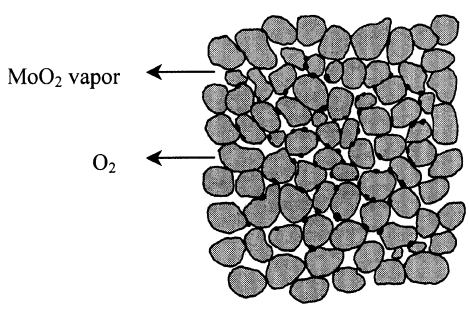

(c)

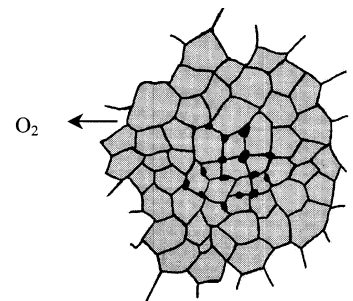

$(d)$

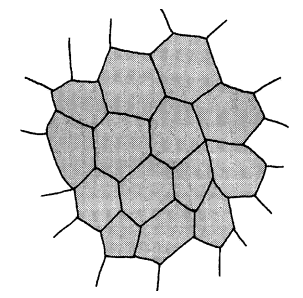

(e)

Fig. 15-The schematics showing the deoxidation mechanisms of molybdenum compacts when sintered under vacuum: $(a)$ green compact with $\mathrm{MoO}_{3}$ films on particles, $(b) \mathrm{MoO}_{3}$ in outer sections evaporates while $\mathrm{MoO}_{3}$ in the center section reacts with molybdenum forming $\mathrm{MoO}_{2}$ particles, $(c)$ evaporation of $\mathrm{MoO}_{2}$ until all pores are isolated, $(d)$ deoxidization proceeds through decomposition of $\mathrm{MoO}_{2}$, and $(e)$ grain growth after complete deoxidation.

form $\mathrm{MoO}_{2}$, as shown in Figure 15(b). As the temperature further increases, some of the $\mathrm{MoO}_{2}$ evaporates and escapes to the ambient environment through the open pore channels, while some of it decomposes because the oxygen pressure is extremely low in the atmosphere of the graphite furnace (Figure 15(c)). As sintering enters the final stage, as illustrated in Figure 15(d), pores begin to close and the evaporation mechanism stops. During this final stage of sintering, the decomposition becomes the dominant mechanism. The decomposed oxygen atoms could diffuse through the grain boundaries or through the bulk and evaporate at the surface. This is a diffusion-controlled step, and, thus, a long sintering time is required for complete deoxidation of the $\mathrm{MoO}_{2}$.

\section{CONCLUSIONS}

When molybdenum compacts are sintered under vacuum at $4 \mathrm{~Pa}$, the ductility increases as the sintering time increases, despite coarsening in the grain size. This is mainly attributed to the reduction of the $\mathrm{MoO}_{2}$ particles, which are located mostly at the triple points and at the grain boundaries. Evidence of ductile fracturing can be found on 4-mm-thick specimens after 10 hours of sintering at $1750^{\circ} \mathrm{C}$, at which point the oxygen content decreases from $9270 \mathrm{ppm}$ in the green compact to $170 \mathrm{ppm}$.

Two mechanisms are responsible for the molybdenum deoxidation. The first one is the evaporation of $\mathrm{MoO}_{3}$ and $\mathrm{MoO}_{2}$, while the second one is the decomposition of $\mathrm{MoO}_{2}$. In the initial stage of the sintering, deoxidation is dominated by the evaporation of the $\mathrm{MoO}_{3}$ films on powder surfaces, particularly those near the outside of the compact. The remaining oxides, which are mostly located in the center section of the compact, react with molybdenum, forming $\mathrm{MoO}_{2}$. When compacts are further heated and are under high vacuum, the $\mathrm{MoO}_{2}$ evaporates and escapes through interconnected pore channels to the ambient. In the case of graphite furnaces, the oxygen partial pressure in the atmosphere is low enough, and thus the decomposition mechanism also proceeds in parallel. As sintering enters the final stage, during which most pores are isolated, the evaporation mechanism stops and the deoxidation of molybdenum proceeds mainly through decomposition of the $\mathrm{MoO}_{2}$.

\section{ACKNOWLEDGMENTS}

The authors thank the National Science Council of the Republic of China for their support of this work under Contract No. NSC 89-2216-E-002-021.

\section{REFERENCES}

1. Y. Hiraoka and M. Okada: Z. Metallkd., 1987, vol. 78 (3), pp. 197-200.

2. F. Morito: J. Mater. Sci., 1989, vol. 24, pp. 3403-10.

3. G. Kohistrung, H. Marx, J. Bresch, M. Leich, and I. Kalning: Powder Metall. Int., 1986, vol. 18 (6), pp. 414-16.

4. L.E. Olds and G.W.P. Rengstorff: J. Met., 1956, vol. 8, pp. 150-55.

5. A.V. Krajnikov, A.S. Drachinskiy, and V.N. Slyunyaev: Refractory Met. Hard Mater. 1992, vol. 11, pp. 175-80.

6. Standard Specification for Molybdenum and Molybdenum Alloy Plate, Sheet, Strip, and Foil, ASTM B-386-91, ASTM, Philadelphia, PA, 1997.

7. L. Brewer and G.M. Rosenblatt: Trans. TMS-AIME, 1962, vol. 224, pp. 1268-71.

8. K. Ono and J. Moriyama: Metall. Trans. B, 1982, vol. 13B, pp. 241-49.

9. S.C. Srivastava and L.L. Seigle: Metall. Trans., 1974, vol. 5, pp. 49-52.

10. E. Fromm and H. Jehn: Metall. Trans., 1972, vol. 3, pp. 1685-92.

11. H.A. Jehn and K.K. Schulze: in Physical Metallurgy and Technology of Molybdenum and Its Alloys, K.H. Miska, M. Semchyshen, and E.P. Whelan, eds., AMAX Inc., Ann Arbor, MI, 1985, pp. 107-17.

12. F. Morito: J. Met., 1993, vol. 45 (6), pp. 54-58.

13. M.W. Chase, C.A. Davies, J.R. Downey, D.J. Frurip, R.A. McDonald, and A.N. Syverud: JANAF Thermochemical Tables, 3rd ed., American Chemical Society and the American Institute of Physics for the National Bureau of Standards, Midland, MI, 1985, p. 1516. 